\title{
Childhood asthma: A best-practice strategy for diagnosis and assessment of control in South Africa
}

\author{
A van Niekerk, ${ }^{1} \mathrm{MB}$ ChB, MMed (Paed); D A White, ${ }^{2} \mathrm{MB}$ BCh, FC Paed (SA), MMed (Paed), Dip Allerg (SA), Cert Pulmonology (SA) Paed; \\ P Goussard, ${ }^{3}$ PhD; S M Risenga, ${ }^{4}$ BSc, MB ChB, MMed (Paed), DCH, Dip Allerg (SA), Cert Pulmonology (SA) Paed \\ ${ }^{1}$ Department of Paediatrics and Child Health, School of Medicine, Faculty of Health Sciences, University of Pretoria, and Steve Biko Academic \\ Hospital, Pretoria, South Africa \\ ${ }^{2}$ Department of Paediatrics and Child Health, Faculty of Health Sciences, University of the Witwatersrand, and Charlotte Maxeke Johannesburg \\ Academic Hospital, South Africa \\ ${ }^{3}$ Department of Paediatrics and Child Health, Faculty of Health Sciences, Stellenbosch University, and Tygerberg Hospital, Cape Town, South Africa \\ ${ }^{4}$ Department of Paediatrics and Child Health, Faculty of Health Sciences, University of Limpopo, and Pietersburg Hospital, South Africa
}

Corresponding author: A van Niekerk(andre@prakmed.co.za)

The South African (SA) Childhood Asthma Working Group of the Allergy Society of SA (ALLSA) advises on best-practice strategy for childhood asthma management. The strategy is in accordance with current evidence and consensus. The aim of this review is to inform on a best-practice strategy for asthma diagnosis and the assessment of asthma control in SA children who attend public and private healthcare services. The diagnosis of asthma is more difficult in preschool-aged than school-aged children. This review proposes a four-step diagnostic approach in both groups, with an added obligation to objectively measure variable expiratory airflow limitation in school-aged children. Asthma control refers to the degree to which the effects of asthma can be seen in patients, or to which these have been reduced by treatment. After initiation of treatment, it is essential to assess asthma control at regular follow-up visits, and to adjust treatment accordingly. Patient education is key to attaining control.

S Afr Med J 2021;111(8):705-709. https://doi.org/10.7196/SAMJ.2021.v111i5.15851

Asthma should be diagnosed in children who present with episodes of variable expiratory airflow limitation. An accurate diagnosis relies on the clinical skills of the clinician. The clinical diagnosis should be supported by objective measurements, such as lung function testing, in school-aged children.

The symptoms of asthma may include episodic wheeze (owing to bronchoconstriction), shortness of breath, difficult or laboured breathing, chest tightness and reduced activity with or without cough. The intensity varies over time, and symptoms improve after a correctly administered rapid-acting inhaled bronchodilator. ${ }^{[1]}$ More than one symptom is usually present. An isolated cough is seldom due to asthma. The variation in symptoms may be triggered by factors such as viral airway infections, allergens, irritants, cold air, exercise and sudden emotional changes (e.g. crying or laughing).

The symptoms are not specific to asthma, and other conditions may mimic the disease. Chronic airway inflammation with variable expiratory airflow limitation defines asthma. It is unfortunately difficult to directly measure airway inflammation and variable expiratory airflow inflammation in young children. Every opportunity should be exploited to define and demonstrate these two key features. The child should show clinical improvement after a correctly administered inhaled bronchodilator, or during a 2 - 3-month pragmatic trial of correctly administered inhaled controller treatment, with worsening of symptoms after treatment cessation, before asthma can be diagnosed. A four-step diagnostic approach is supported.

\section{The four-step diagnostic approach in preschool-aged children}

One in three children will wheeze before their third birthday. Young children are prone to recurring viral airway infections, with which wheeze can be associated. Deciding when this is an initial manifestation of asthma can be difficult. There are many other reasons for wheezing in preschool-aged children. Asthma must therefore be distinguished from these other causes. A practical approach is to follow four basic steps to distinguish asthmatic children from children who wheeze because of an alternative cause. These steps include: detailed history-taking; a clinical examination to exclude an alternative reason for wheezing; assessing inflammation; and seeking objective evidence of variable airflow limitation.

\section{Step 1: Detailed history-taking}

The history is often the most helpful instrument in diagnosing preschoolaged asthma. It should focus on two important aspects: a background history to signal the risk for the inception of asthma; and the history related to the wheeze episodes or 'chest events' themselves (Table 1). ${ }^{[2]}$

The inception of asthma is associated with a number of risk factors. The influence of the genome (e.g. parental asthma or asthma in firstdegree relatives), epigenetic expression (e.g. caesarean section birth or maternal smoking during pregnancy), dysbiosis (e.g. with formula feeding and early antibiotic use), the early development of allergic sensitisation $^{[3]}$ and recurrence of wheeze associated with viral (or bacterial) airway infections are associated with an increased risk for the inception of asthma. ${ }^{[4]}$ Early airway colonisation with encapsulated pathogen ${ }^{[5]}$ and a past personal history of other allergic disease (such as atopic dermatitis or allergic rhinitis) also indicate an increased risk for the inception of asthma.

The history related to the wheeze episodes (or 'chest events') themselves provides helpful information with regard an asthma diagnosis. The decision to consider an asthma diagnosis, and to start controller therapy, is often primarily determined by:

- A history of variability of airflow limitation: Clinicians must make efforts, at every opportunity, to document the response to 
Table 1. Features in history to support an asthma diagnosis, especially in preschool-aged children ${ }^{[2]}$

\begin{tabular}{ll}
\hline Feature & Characteristic suggesting asthma \\
\hline $\begin{array}{l}\text { Past or family history } \\
\text { Cough }\end{array}$ & $\begin{array}{l}\text { Other allergic disease (atopic dermatitis or allergic rhinitis); asthma in first-degree relatives } \\
\text { Recurrent or persistent non-productive cough that may be worse at night or accompanied by some } \\
\text { wheezing and breathing difficulties; cough occurring with exercise, laughing, crying or exposure to } \\
\text { tobacco smoke in the absence of an apparent respiratory infection } \\
\text { Recurrent wheezing, including during sleep or with triggers such as activity, laughing, crying or exposure } \\
\text { to tobacco smoke or air pollution }\end{array}$ \\
Wheeze & Occurring with exercise, laughing, or crying
\end{tabular}

shortness of breath

Reduced activity

Not running, playing or laughing at the same intensity as other children; tires earlier during walks (wants to be carried)

\section{Table 2. Alternative reasons for wheezing in children}

\begin{tabular}{lll}
\hline Infective & Structural & Functional \\
\hline Bronchiolitis & Tracheo- and bronchomalacia & Wheezy phenotypes \\
Atypical infection & Tracheal webs; tracheal and bronchial stenosis & Primary ciliary dyskinesia \\
Bacterial airway infection & Lymphadenopathy; tumours & Cystic fibrosis \\
Laryngotracheobronchitis & Vascular compression: & Gastro-oesophageal reflux disease \\
& - double aortic arch & \\
& - innominate artery compression & \\
& $\bullet$ patent ductus arteriosus ligament & \\
Protracted bacterial bronchitis & Cystic lesions and masses & \\
& H-type tracheo-oesophageal fistula & Retained foreign body \\
& Laryngeal clefts & Pulmonary oedema/cardiac disease \\
& & Interstitial lung disease \\
& & Bronchiolitis obliterans \\
& & Bronchopulmonary dysplasia
\end{tabular}

a correctly administered rapid acting bronchodilator. A history of (preferably doctor-confirmed) bronchodilator responsiveness will support an asthma diagnosis.

- Severity of 'chest events': A history of more severe wheeze (e.g. with respiratory distress or a need for oxygen supplementation) will favour an asthma diagnosis but not exclude alternative diagnoses.

- Frequency and duration of episodes: Events that occur more frequently ( $>3$ episodes per year) and that last longer ( $>10$ days at a time) may indicate an asthma diagnosis, but will not exclude an alternative diagnosis.

- Temporal pattern of symptoms: 'Chest events' that do not only occur during airway infections, but also in response to other triggers in between infections, will support an asthma diagnosis. Events that persist $>3$ years of age, night-time worsening, an association with exercise or environmental change (e.g. cold air exposure) will further support an asthma diagnosis.

\section{Step 2: Exclude an alternative reason for wheezing}

The next step is to consider an alternative diagnosis for wheezing. This step is especially important at a younger age. The aim of the clinical examination is often not to find signs of asthma, but rather to document the presence or absence of atopic disease (atopic dermatitis, allergic rhinitis, etc.) and to seek clinical findings that would indicate an alternative diagnosis (e.g. digital clubbing, growth faltering, asymmetric wheeze, etc.) (Table 2).
Appropriate special investigations (chest X-ray, sweat chloride and contrast studies) may be needed to exclude an alternative diagnosis. A poor response to controller therapy will warrant referral to a specialist for specialised investigations such as bronchoscopy.

\section{Step 3: Assessing inflammation}

Asthma is characterised by chronic airway inflammation. Direct assessment of airway inflammation may not be practical, but indirect cues can inform an opinion on the nature of underlying airway inflammation. Biomarkers that predict asthma, and likely improvement on corticosteroid treatment, include markers of type 2 inflammation such as serum eosinophilia and aeroallergen sensitisation determined through antigen-specific IgE skin-prick testing or ImmunoCAP. Clinical findings of other atopic disease (e.g. atopic dermatitis and allergic rhinitis) may support an asthma diagnosis.

A pragmatic therapeutic trial will confirm the presence of corticosteroid-responsive inflammation. A step-wise trial of correctly administered low-dose inhaled corticosteroid (ICS) should be carried out when starting treatment in any child with a wheezing disorder. Any treatment given should be viewed as a therapeutic trial, and the initial treatment response must be evaluated in 6 - 8 weeks. ${ }^{[2,4,6,7]}$ If there is no clinical response to correctly administered ICS therapy, this should be discontinued, and the child investigated further. Symptoms that resolve during ICS therapy may be due to the natural history of a preschool wheezing disorder or to an effect of treatment. This must 
be distinguished by withdrawing treatment again. Treatment should only be restarted if symptoms recur. An ongoing benefit of ICS treatment should be reviewed every 3 months, and the ICS kept at the lowest possible dose for symptom control. ${ }^{[6-9]}$

\section{Step 4: Seek objective evidence of variable expiratory airflow limitation}

It is seldom possible to perform objective measurements on variable expiratory airflow limitation in young children. A clinical assessment of the response to correctly administered rapid-acting inhaled bronchodilator can be helpful. The clinician should pursue every opportunity to document improvement in wheeze and hyperinflation after the administration of a rapid-acting inhaled bronchodilator. The more it is confirmed clinically, the more likely that the correct diagnosis is asthma; and conversely the more it cannot be confirmed clinically, the more unlikely an asthma diagnosis will be.

\section{Diagnosing asthma in school-aged children}

For children $>6$ years of age, the same diagnostic steps should be followed. A proper history, exclusion of an alternative reason for wheezing and an assessment for inflammation should still be undertaken. Objective evidence of variable expiratory airflow limitation can now be demonstrated, and should ideally be investigated before commencement of controller therapy. Peak expiratory flow (PEF) measurements or preferably spirometry can be used (Table 3) ${ }^{[10]}$ Normal tests do not exclude the diagnosis of asthma. ${ }^{[11]}$ In the case that the history is suggestive of asthma, and the spirometry does not support the diagnosis, other specialised tests such as exercise bronchoprovocation or methacholine challenge may be done by a pulmonologist to confirm the diagnosis.

\section{Assessment of asthma control and future risk}

Asthma control means the extent to which the effects of asthma can be seen in the patient, or to which they have been reduced or removed by treatment. ${ }^{[2]}$ Evaluation of asthma control includes two broad concepts, namely symptom control and future risk of adverse outcomes. Symptom control is assessed by frequency of symptoms, reliever medication use and activity limitation over the last week and month. Formal tools that provide scores to distinguish levels of symptom control (e.g. the Childhood Asthma Control Test (c-ACT) and Asthma Control Questionnaire (ACQ)) can offer insight into asthma control. ${ }^{[12]}$ Future risk refers to the possibility of exacerbations, medication side-effects (oral symptoms and growth in children) or loss of lung function. No test is a gold standard, and all tests must be used in conjunction with a good history and clinical examination to assess control. ${ }^{[13,14]}$ After initiation of treatment, it is essential to assess asthma control at every follow-up visit, no less than 6-monthly, and to adjust treatment accordingly.

Asthma control is significantly more likely in patients who are educated (know their disease), are regularly taught to use the inhaler device, are encouraged to use controller medication regularly and have a written action plan and educational material (www. allergyfoundation.co.za). It is important in patients with problematic severe asthma to distinguish between 'difficult asthma' due to poor adherence and/or incorrect inhaler technique and/or environmental or social factors, 'asthma plus' due to associated comorbidities, and true 'severe therapy-resistant asthma. ${ }^{[15]}$ If control is sub-optimal, check for all reasons, and educate the patient. A small number of patients need treatment adjustment (Tables 4 and 5).

\section{Goals of asthma treatment}

The long-term goals of asthma management include the following:

- to achieve good symptom control

- to maintain normal activity levels

- to minimise future risk of asthma-related mortality

- to reduce exacerbations

- to maintain lung function and normal lung development

- to minimise side-effects of treatment

- to provide a written action plan

- to consider the patient's own goals with regard to treatment

\title{
Table 3. Confirmation of variable airflow limitation with PEF or spirometry (adapted from Masekela et al. ${ }^{[10]}$ )
}

\author{
For PEF measurements \\ PEF variability with an average daily diurnal variability $>13 \%$ when documented twice daily for 2 weeks \\ Positive exercise challenge test with decrease in PEF $>15 \%$ after reaching target heart rate of $0.8 \times 220$ minus age in years \\ Excessive variation of PEF $>15 \%$ between outpatient visits (using same equipment) with or without airway infections \\ For spirometry measurements \\ Decreased $\mathrm{FEV}_{1} / \mathrm{FVC}$ ratio due to decreased $\mathrm{FEV}_{1}$ (normal ratio $>0.9$ ) \\ Positive bronchodilator reversibility with increase in $\mathrm{FEV}_{1}>12 \%$ \\ Positive exercise challenge test with decrease in $\mathrm{FEV}_{1}>12 \%$ after reaching target heart rate of $0.8 \times 220$ minus age in years \\ Excessive variation of $\mathrm{FEV}_{1}>12 \%$ between outpatient visits (using same equipment) with or without airway infections
}

$\mathrm{PEF}=$ peak expiratory flow; $\mathrm{FEV}_{1}=$ forced expiratory volume in 1 second; $\mathrm{FVC}=$ forced vital capacity

Table 4. GINA assessment of asthma symptom control in children aged 6 - 11 years, adolescents and adults

\begin{tabular}{llll}
\hline Symptom control & Well controlled & Partly controlled & Uncontrolled \\
\hline In the past 4 weeks, has the patient had: & None of these & $1-2$ of these & $3-4$ of these \\
- daytime asthma symptoms (wheeze, chest tightness, & & \\
shortness of breath, cough) more than twice per week? & & \\
- any night-time awakening due to asthma? & & \\
- reliever (SABA) use more than twice per week? & & \\
- limitation of activity - sport and school? & & \\
GINA = Global Initiative for Asthma; SABA = short-acting beta-2 agonist. &
\end{tabular}




\begin{tabular}{|c|c|c|c|}
\hline \multicolumn{2}{|c|}{ Measures of asthma control } & \multicolumn{2}{|l|}{ Risk factors for poor asthma outcomes } \\
\hline \multirow[t]{15}{*}{ History } & $\begin{array}{l}\text { Uncontrolled symptoms (as } \\
\text { in Table 4) (plus or minus } \\
\text { symptom control scores e.g } \\
\text { c-ACT, ACQ }\end{array}$ & - & Risk of exacerbations \\
\hline & Exacerbations & $\begin{array}{l}\geq 1 \text { severe exacerbation in last } 12 \text { months } \\
\text { ICU (plus or minus intubation) }\end{array}$ & Risk of exacerbations \\
\hline & Birth history & $\begin{array}{l}\text { Preterm birth } \\
\text { Low birth-weight } \\
\text { Greater infant weight gain }\end{array}$ & $\begin{array}{l}\text { Risk factors for development of persistent airflow } \\
\text { limitation }\end{array}$ \\
\hline & Past medical history & Bronchiolitis & $\begin{array}{l}\text { Risk factor for development of persistent airflow } \\
\text { limitation }\end{array}$ \\
\hline & Medications & High SABA use & Risk of exacerbations \\
\hline & & Incorrect inhaler technique & Risk of exacerbations and persistent airflow limitation \\
\hline & & Poor adherence & Risk factors for local and systemic medication side- \\
\hline & & Inadequate ICS & effects \\
\hline & & No ICS & Poorly controlled asthma can affect growth (check \\
\hline & & Frequent OCS & child's height at least yearly) \\
\hline & & Long-term, high-dose ICS & $\begin{array}{l}\text { Growth velocity may be lower in the first } 1-2 \text { years of } \\
\text { ICS treatment } \\
\text { Local side-effect includes oral thrush }\end{array}$ \\
\hline & Comorbidities & Obesity & Risk factors for poor asthma control \\
\hline & & $\begin{array}{l}\text { Chronic rhinosinusitis } \\
\text { GORD } \\
\text { Confirmed food allergy } \\
\text { Obstructive sleep apnoea } \\
\text { Pregnancy }\end{array}$ & $\begin{array}{l}\text { Confirmed food allergy is a risk factor for asthma- } \\
\text { related death }\end{array}$ \\
\hline & Exposures & $\begin{array}{l}\text { Tobacco smoke } \\
\text { Allergen exposure if sensitised (e.g. house } \\
\text { dust mite, cockroach, pets, mould) } \\
\text { Indoor or outdoor air pollution }\end{array}$ & Risk of exacerbations \\
\hline & Psychosocial & $\begin{array}{l}\text { Psychological - depression, anxiety } \\
\text { Socioeconomic - poor access to care, lack of } \\
\text { education }\end{array}$ & Risk of exacerbations \\
\hline \multirow[t]{7}{*}{$\begin{array}{l}\text { Lung } \\
\text { function } \\
\text { tests }\end{array}$} & $\begin{array}{l}\mathrm{FEV}_{1} \text { Measure at start of } \\
\text { treatment, after } 3-6 \text { months } \\
\text { of controller treatment, } \\
\text { periodically thereafter }\end{array}$ & Low FEV & Risk of exacerbations and lung function decline \\
\hline & $\mathrm{FEV}_{1} / \mathrm{FVC}$ & $\mathrm{FEV}_{1} / \mathrm{FVC}<0.90$ & Risk of exacerbations \\
\hline & $\begin{array}{l}\text { Persistent bronchodilator } \\
\text { reversibility }\end{array}$ & Increase of $\mathrm{FEV}_{1}>12 \%$ predicted & $\begin{array}{l}\text { Suggests uncontrolled asthma } \\
\text { Risk factor for adverse outcome }\end{array}$ \\
\hline & PEFR & $\begin{array}{l}\text { Short-term twice daily readings } \\
\text { Average daily diurnal PEF variability }>13 \% \\
\text { (day's highest - day's lowest)/mean of day's } \\
\text { highest and lowest, averaged over } 1 \text { week }\end{array}$ & $\begin{array}{l}\text { Suggests uncontrolled asthma and increases risk of } \\
\text { exacerbations }\end{array}$ \\
\hline & $\begin{array}{l}\text { Additional tests although not } \\
\text { routine }\end{array}$ & & Risk of exacerbations \\
\hline & $\mathrm{FeNO}$ & Elevated $\geq 35 \mathrm{ppb}$ & \\
\hline & Exercise challenge & $\begin{array}{l}\text { Assess airway hyper-responsiveness and } \\
\text { fitness } \\
\text { Fall in } \mathrm{FEV}_{1}>12 \% \text {, PEF }>15 \%\end{array}$ & \\
\hline Blood & Eosinophilia & - & Risk factor for persistent airflow limitation \\
\hline Sputum & Eosinophilia & - & Risk factor for persistent airflow limitation \\
\hline
\end{tabular}


The goals of asthma management can only be achieved through a good understanding between the patient/parent/caregiver and the medical team. A cycle of assess (diagnosis, symptom control, risk factor assessment, medication technique and adherence), adjust treatment (medications, non-pharmacological strategies, treatment of modifiable risk factors) and review response (medication effects and side-effects), in combination with education of both the parent/ caregiver and the child with regard to effective inhaler use, adherence, symptom monitoring and a written personalised action plan, should be carried out at every visit. Medication should be adjusted up or down depending on the level of asthma control, and the lowest effective dose of ICS should always be sought.

\section{Conclusion}

The diagnosis of asthma in a child, especially at preschool age, can be complex, and should be considered in any child with recurrent episodes of wheeze and tight chest with or without cough that vary over time and improve after a correctly administered rapid-acting inhaled bronchodilator. Assessment of airway inflammation and objective evidence of variable expiratory limitation should be sought at every opportunity. Asthma control refers to the degree to which the manifestations and risk of asthma have been reduced by effective management, and should be assessed at every visit. Measuring control helps to determine whether treatment should be adjusted up or down or maintained. Patient education is key to attaining the goals of asthma management.

Declaration. None.

Acknowledgements. None.
Author contributions. Equal contributions.

Funding. None.

Conflict of interest. None.

1. Motala C, Green RJ, Manira AI, Potter PC, Zar HJ. Guideline for the management of chronic asthma in children - 2009 update. S Afr Med J 2009;99(12):897-912.

Global Initiative for Asthma. Global Strategy for Asthma Management and Prevention, 2020. Available from www.ginasthma.org (a. Accessed 1 March 2021).

3. Sly PD, Boner AL, Bjorksten B, et al. Early identification of atopy in the prediction of persistent asthma in children. Lancet 2008;372:1 100-1106. https://doi.org/10.1016/S0140-6736(08)61451-8

4. Jackson DJ, Gern JE, Robert F, et al. The contributions of allergic sensitization and respiratory pathogens to asthma inception. J Allergy Clin Immunol 2016;137(3):659-665. https://doi org/10.1016/j.jaci.2016.01.002

5. Bisgaard H, Hermansen MN, Buchvald F, et al. Childhood asthma after bacterial colonization of the airway in neonates. N Engl J Med 2007;357:1487-1495. https://doi.org/10.1056/NEJMoa052632

6. Brand PLP, Caudri D, Eber E, et al. Classification and pharmacological treatment of preschool wheezing Changes since 2008. Eur Respir J 2014;43(4):1172-1177. https://doi.org/10.1183/09031936.00199913 7. Bush A, Ngakumar P. Preschool wheezing phenotypes. Eur Med J 2016;1(1):93-101.

8. Bisgaard H, Hermansen MN, Loland L, Halkjaer LB, Buchvald F. Intermittent inhaled corticosteroid in infants with episodic wheezing. N Engl J Med 2006;354(19):1998-2005. https://doi.org/10.1056/ NEJMoa054692

9. Guilbert T, Morgan WJ, Zeiger RS, et al. Long-term inhaled corticosteroids in preschool children at high risk for asthma. N Engl J Med 2006;354(19):1985-1997. https://doi.org/10.1056/NEJMoa051378

10. Masekela R, Risenga SM, Kitchin OP, et al. The diagnosis of asthma in children: An evidence-based approach to a common clinical dilemma. S Afr Med J 2018;108(7):540-545. https://doi.org/10.7196 SAMJ.2018.v108i7.13167

11. Galant SP, Morphew T, Newcomb RL, Hioe K, Guijon O, Liao O. The relationship of the bronchodilator response to poor asthma control in children with normal spirometry. J Pediatr 2011;158(6):953-958. response to poor asthma control in childre
https://doi.org/10.1016/j.jpeds.2010.11.029

12. Deschildre A, Pin I, El Abd K, et al. Asthma control assessment in a pediatric population: Comparison between GINA/NAEPP guidelines, Childhood Asthma Control Test (C-ACT), and physician's rating. between GINA/NAEPP guidelines, Childhood Asthma Con

13. Green RJ, Klein M, Becker P, et al. Disagreement between common measures of asthma control in
13. Green RJ, Klein M, Becker P, et al. Disagreement between common measu
children. Chest 2013;143(1):117-122. https://doi.org/10.1378/chest.12-1070

14. Dinakar C, Chipps BE, AAP Section on Allergy and Immunology, AAP Section on Pediatric Dinakar C, Chipps BE, AAP Section on Allergy and Immunology, AAP Section on Pediatric
Pulmonology and Sleep Medicine. Clinical tools to assess asthma control in children. Pediatrics 2017;139(1):e20163438. https://doi.org/10.1542/peds.2016-3438

15. Bush A, Fleming L, Sagalani S. Severe asthma in children. Respirology 2017;22(5):886-897. https:// doi.org/10.1111/resp. 13085

Accepted 2 June 2021. 